\title{
Space and Unemployment: The Labor- Market Effects of Spatial Mismatch
}

\author{
Jan K. Brueckner, University of Illinois at \\ Urbana-Champaign
}

Yves Zenou, University of Southampton

\begin{abstract}
The aim of this article is to analyze the effects of housing discrimination on the wages and unemployment rates of black workers. The unemployment effect is first analyzed using a simple minimum-wage model. An efficiency-wage model is then adopted in order to endogenize both unemployment and wages. Under both models, suburban housing discrimination leads to a higher unemployment rate for blacks in the central city than in the suburbs. Under the efficiencywage model, black wages are also lower in the center. The analysis thus generates a link between unemployment and a seemingly unrelated phenomenon: racial discrimination in the housing market.
\end{abstract}

\section{Introduction}

The spatial mismatch hypothesis, first enunciated by Kain (1968), argues that poor labor market outcomes for black workers are partly the result of a growing spatial separation between their residences and the locations of jobs. This separation, it is argued, has been caused by job decentralization in U.S. cities combined with restricted residential mobility for black households.

This research was initiated while the first author was a visitor at CERASENPC and Université du Maine. He thanks these institutions for their hospitality. In addition, we thank Stuart Rosenthal and Stephen Ross for helpful comments. Finally, seminar participants at the University of British Columbia and Washington University in St. Louis provided helpful suggestions.

[Journal of Labor Economics, 2003, vol. 21, no. 1]

(C) 2003 by The University of Chicago. All rights reserved. 0734-306X/2003/2101-0008\$10.00 
Table 1

Annual Rates of Net Employment Change

\begin{tabular}{lrrrrr}
\hline & \multicolumn{2}{c}{$1969-79$} & & \multicolumn{2}{c}{$1979-87$} \\
\cline { 2 - 3 } \cline { 5 - 6 } & Central City & Suburbs & & Central City & Suburbs \\
\hline New York & -1.3 & 2.2 & & 1.2 & 2.9 \\
Chicago & .4 & 3.5 & & .3 & 3.5 \\
Philadelphia & -2.0 & -2.2 & & -.2 & 2.8 \\
Los Angeles & 2.3 & 6.9 & & 2.0 & 4.3 \\
Atlanta & 2.1 & 5.2 & & 2.1 & 7.3 \\
Boston & .3 & 2.1 & & 1.6 & 3.0 \\
Dallas & 3.7 & 5.3 & & 3.7 & 7.5 \\
Detroit & .6 & 3.7 & & -1.6 & 2.5 \\
Washington & .4 & 3.9 & & .9 & 4.8 \\
\hline \multicolumn{1}{l}{ Soun }
\end{tabular}

SOURCE.-Stanback (1991).

The ingredients of the mismatch hypothesis are highlighted in tables 1,2 , and 3 . Table 1 documents the phenomenon of job decentralization by showing that employment growth in the suburbs has outstripped central-city job growth in the major U.S. metropolitan areas. Table 2 shows that, despite this differential employment growth, the locations of black residences in 1990 remained strongly skewed toward the central city. Suburban housing discrimination against blacks is a common explanation for this failure of residences to follow jobs. Table 3 completes the picture by adding information on labor market outcomes. It shows that unemployment for central city blacks is much higher than for suburban blacks, with black labor force participation also depressed in the central city relative to the suburbs. Both disparties are larger for blacks than for other racial groups. The poor central city outcomes for blacks, it is argued, are partly a result of the mismatch between the locations of jobs and black residences.

Dozens of papers have attempted to test the spatial mismatch hypothesis, and surveys of this empirical literature are provided by Holzer (1991), Kain (1992), and Ihlanfeldt and Sjoquist (1998). The typical approach is to look for a relationship between job accessibility and labor-market outcomes for blacks, using various levels of aggregation of the data. For example, these outcomes are measured at the individual level by Ihlanfeldt and Sjoquist (1990), at the neighborhood level by Raphael (1998), and at the metropolitan level by Weinberg (2000). Most of the studies in this literature find support for the mismatch hypothesis. ${ }^{1}$

${ }^{1}$ Using a different approach, Zax and Kain (1996) provide one of the most striking empirical confirmations of the mismatch hypothesis. They show that when a particular Detroit firm relocated to the suburbs, its black employees were likely to quit rather than relocate their residences, in contrast to the behavior of the white employees. More generally, Cutler and Glaeser (1997) demonstrate that housing segregation lowers the welfare of blacks, and one of the reasons they propose is that segregation reduces job access for black workers. 
Table 2 Black Population Shares in Central Cities and Suburbs, 1990

\begin{tabular}{lcc}
\hline & Percent Black in Central City & Percent Black in Suburbs \\
\hline New York & 29 & 12 \\
Chicago & 39 & 7 \\
Philadelphia & 40 & 9 \\
Los Angeles & 14 & 9 \\
Atlanta & 67 & 19 \\
Boston & 26 & 2 \\
Dallas & 30 & 7 \\
Detroit & 76 & 5 \\
Washington & 66 & 19 \\
\hline \multicolumn{2}{c}{ Source.-The State of the Nation's Cities, Version 2.2a, online database, 1998.} &
\end{tabular}

Despite the growth of a large empirical literature, little effort has been spent in exploring the theoretical foundations of the spatial mismatch hypothesis. The only existing studies are by Brueckner and Martin (1997, with a follow-up paper by Martin [1997]); Coulson, Laing, and Wang (2001); Anas (1998); and Arnott (1998). In its own way, each study attempts to provide a model that generates predictions consistent with the stylized facts outlined above. Brueckner and Martin (1997) propose a spatial model where suburban housing discrimination prevents black households from following jobs to the suburbs. By itself, the resulting housing-market distortion leads to lower black welfare, and this outcome is compounded when labor-market effects are added to the analysis. However, use of a neoclassical market-clearing model rules out unemployment, a major focus of the empirical literature, making the model's depiction of spatial mismatch incomplete. The models of Anas (1998) and Arnott (1998) offer less spatial detail, and they also rely on simple labor markets that are incapable of generating unemployment effects as part of spatial mismatch.

The search model of Coulson et al. (2001) comes closer to providing insight into some of the labor-market impacts that have concerned empirical researchers. These authors assume that the entry cost of firms is higher in the central business district (CBD) than in the suburbs and that some workers are willing to accept longer commutes than others. These assumptions affect the matching process between firms and workers, leading to a higher unemployment rate for central city residents than for suburban residents and the possibility of reverse commuting, with higher wages earned in the suburbs. The main drawback of the model is that there is no specific analysis of blacks versus whites, and the distortion is on the firms' side through a higher entry cost in the CBD.

The purpose of this article is to offer a new theoretical analysis that provides a simple and comprehensive picture of the effects of spatial mismatch in the labor market. The model, which borrows elements of 
Table 3 Labor-Market Outcomes in the 25 Largest Cities and Their Suburbs, 1997

\begin{tabular}{lccccc}
\hline & \multicolumn{2}{c}{$\begin{array}{c}\text { Labor Force } \\
\text { Participation Rate }\end{array}$} & & \multicolumn{2}{c}{ Unemployment Rate } \\
\cline { 2 - 3 } & Central City & Suburbs & & Central City & Suburbs \\
\hline Total & 64.6 & 69.6 & & 7.3 & 4.0 \\
White & 66.2 & 69.8 & & 5.5 & 3.7 \\
Black & 60.2 & 73.3 & & 12.5 & 7.6 \\
Hispanic origin & 64.3 & 71.3 & & 8.1 & 6.1 \\
\hline
\end{tabular}

Source.-Current Population Survey, 1998.

the Brueckner-Martin (1997) framework, is explicitly spatial, and it realistically concentrates black residences in the central city via the assumption of suburban housing discrimination. Because of this residential concentration, the black labor force is skewed toward the CBD labor market, with relatively few blacks attached to the suburban labor market. This distorted pattern generates the main conclusions of the article. The analysis shows that the mismatch-induced enlargement of the black CBD work force leads to an unemployment differential between the two labor markets. The unemployment rate among black CBD workers is higher than the rate among black suburban workers, an outcome that is consistent with the evidence shown in table 3 .

To show the robustness of this conclusion, the result is established under two alternate models of the labor market, both of which yield unemployment as an equilibrium outcome. The first model is a simple minimum-wage framework. The CBD and suburban labor markets are assumed to have identical demands for unskilled black labor, while facing a common minimum wage. Then, the skewed allocation of the black work force caused by suburban housing discrimination yields a higher black unemployment rate in the $\mathrm{CBD}$ than in the suburbs.

To demonstrate that this conclusion need not rely on a model with artificially fixed wages, the analysis shows that a CBD-suburban unemployment differential for blacks also emerges in an efficiency-wage model. In such a model, unemployment serves as a worker discipline device, keeping employees from shirking on the job. Housing discrimination once again skews the black labor pool toward the CBD labor market, and in order to induce central-city firms to absorb these workers, a lower wage is required, as predicted by the mismatch hypothesis. But to prevent shirking, the reduction in work incentives caused by the lower CBD wage must be offset by a CBD unemployment rate above that in the suburbs, which raises the penalty from job termination. These results are derived using the efficiency-wage framework of Shapiro and Stiglitz (1984).

In analyzing the CBD-suburban unemployment differential for blacks, this article forges a novel link between labor-market outcomes and an 
apparently unrelated phenomenon: racial discrimination in the housing market. Furthermore, the analysis shows that the strength of this link depends on the friction of space, as reflected in commuting costs. In particular, the gap between the central and suburban unemployment rates grows as commuting costs rise. Overall, the discussion offers a useful theoretical picture of the effects of spatial mismatch, providing some of the missing theoretical underpinnings for the large empirical literature.

It should be noted that the analysis abstracts from the nonminority side of the labor market by assuming that the production function is separable in skilled and unskilled labor. Therefore, labor market outcomes for (skilled) whites are determined independently of those for blacks. For concreteness, white wages can be viewed as the result of a standard marketclearing process, with the minimum-wage or efficiency-wage models not relevant and unemployment absent. In this regard, it must be borne in mind that the goal of the analysis is not to compare labor market outcomes for blacks and whites. Instead, the goal is to contrast these outcomes for black CBD and suburban workers.

The plan of the article is as follows. The spatial model is described in Section II, and the minimum-wage model is wedded to it in Section III. The efficiency-wage analysis is presented in Section IV, and Section V offers conclusions.

\section{The Spatial Model}

As explained above, the analytical framework used in this article comes from combining elements of the spatial model of Brueckner and Martin (1997) with the minimum-wage and efficiency-wage models. While the basic version of Brueckner and Martin's model suppresses the labor market by assuming that incomes are fixed for blacks and whites, integration of either of these labor-market frameworks makes incomes endogenous and generates unemployment. To understand the resulting structure, it is helpful to first review aspects of the spatial model, after which the labormarket models are discussed. ${ }^{2}$

For simplicity, the model focuses on a linear city with unit width. The city is occupied by $K$ white residents, each of whom consumes one unit of land, and $N$ black residents, whose individual land consumption equals $\theta$, where $\theta<1$ (reflecting lower black incomes). Since the city's employment areas take up no space, its overall length is then $K+\theta N$. Initially, all jobs are located in an employment center at the left end of the city, denoted the CBD. Employment decentralization then occurs, as documented in table 1, with some jobs moving to a suburban business district

\footnotetext{
${ }^{2}$ For other applications of the efficiency-wage model in a spatial context, see Zenou and Smith (1995), Smith and Zenou (1997), and Brueckner and Zenou (1999).
} 
(SBD) located at the right end of the original city. Residences continue to occupy the same area after formation of the SBD, namely, the interval from $x=0$ to $x=\bar{x} \equiv K+\theta N$, where $x$ denotes distance to the CBD. ${ }^{3}$

As seen below, the assumption of lower black land consumption means that black bid-rent curves, which indicate willingness to pay for land at different locations, are steeper than those of whites. This, in turn, means that, in the original monocentric city, the black residential area is closest to the CBD, with whites living farther out. The black area thus extends from $x=0$ to $x=\theta N$, while the white area extends from $x=\theta N$ to $x=\bar{x}$.

The effect of job decentralization on the residential pattern depends on the extent of suburban housing discrimination against blacks. If blacks are free to live anywhere in the city, then the original residential pattern is replicated around the $\mathrm{SBD}$ as jobs decentralize. Blacks working at the SBD live closest to it, with white SBD commuters living outside it (i.e., closer to the $\mathrm{CBD}$ ). The locations of $\mathrm{CBD}$ commuters mimic the original pattern, although over a smaller area. This "unrestricted" residential pattern, along with the associated bid-rent curves, is shown in figure 1. Note that the bid-rent curves of SBD workers slope upward, while those of $\mathrm{CBD}$ workers are downward sloping.

Alternatively, blacks could face housing discrimination in the suburbs, as documented by Yinger $(1986,1997)$. To draw a sharp distinction from the unrestricted case, the analysis focuses on a situation where housing discrimination is so strong that landlords in the original white part of the city refuse to rent to blacks under any circumstances. In other words, blacks are prevented from living in the interval $[\theta N, \bar{x}]$ regardless of their willingness to pay for land in this area. The resulting "restricted" residential pattern and the associated bid-rent curves are shown in figure 2. Note that, in the restricted case, the racial makeups of the central and suburban parts of the city are skewed in favor of one group, reflecting the pattern seen in table 2 (the exact racial shares depend on the location of the suburban boundary).

To understand the pattern of bid-rent curves in figure 2, observe that housing discrimination means that whites face no competition for suburban land. Blacks, however, must still outbid whites for land in the central part of the city. Therefore, the black bids in this area must be at least as large as the bids offered by white CBD commuters. This, in turn, implies that the minimum point of the black bid-rent curves must lie on the extension of the bid-rent curve of white CBD commuters, as shown in figure 2. Beyond this minimum point, which occurs at $x=\tilde{x}$, figure 2

\footnotetext{
${ }^{3}$ This simplifying assumption, which means that residences cannot relocate to the right of $\bar{x}$ after formation of the SBD, is justified by imagining that the city is located on an island, with a business district at each end.
} 


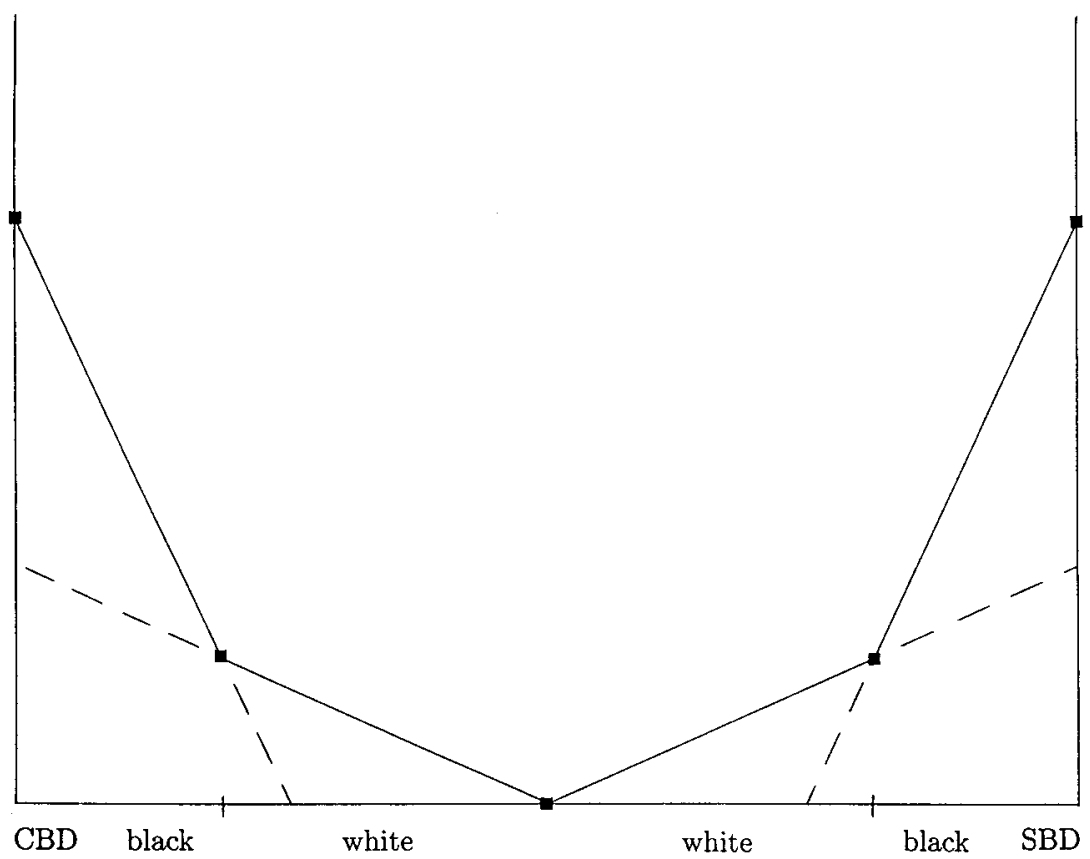

FIG. 1.-The unrestricted equilibrium

shows that a black bid-rent curve slopes upward toward the SBD, indicating that black workers living between $\tilde{x}$ and $\theta N$ choose to commute to the SBD despite its remote location. Figure 2 also shows a dramatic bid-rent discontinuity at $x=\theta N$, with black SBD workers offering much more for land in the white area than the white residents themselves. This discrepancy, which would be unsustainable in a competitive market, is a consequence of discrimination by suburban landlords. ${ }^{4}$

To generate the bid-rent curves shown in the figures, it is assumed that city residents consume a composite good along with land, with the consumption level denoted $Z$ for whites and $z$ for blacks. With land con-

${ }^{4}$ Fixed incomes are assumed in Brueckner and Martin's analysis of figs. 1 and 2, with the incomes of whites and blacks at the CBD and SBD equal to constants that take the same value in the unrestricted and restricted cases. However, to generate the commuting patterns shown in the figures, where each type of worker commutes to both employment centers, the CBD-SBD income differential for each type must not be too great in absolute value. Otherwise, all workers of a given type might favor one employment center over the other. Such restrictions are unneeded when incomes are endogenous. As long as the marginal productivity of labor for each racial group becomes infinite at a zero input level, the only possible pattern has whites and blacks working at both employment centers, as in figs. 1 and 2. 


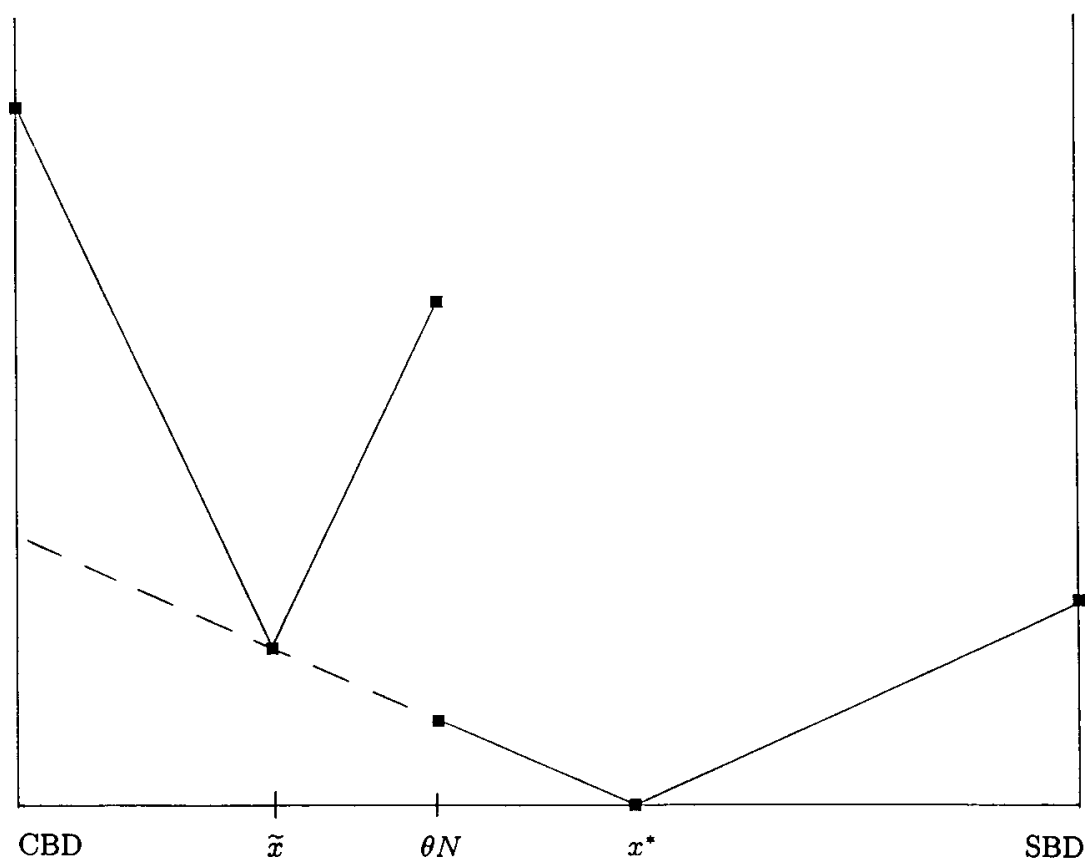

FIG. 2.-The restricted equilibrium

sumption fixed, utility can be represented directly by the level of the composite good. Letting $t$ denote commuting cost per mile, the budget constraints of white and black CBD commuters are then given by $Z+$ $P+t x=Y_{c}$ and $z+\theta p+t x=y_{c}$. In these constraints, $Y_{c}$ and $y_{c}$ are the white and black incomes at the $\mathrm{CBD}$, with $P$ and $p$ giving the rents per unit of land paid by whites and blacks (recall that land consumption levels are fixed, respectively, at 1 and $\theta$ ). Rearranging yields the bid-rent curves for white and black CBD commuters, which are written $P(x)=Y_{c}-$ $t x-Z$ and $p(x)=\left(y_{c}-t x-z\right) / \theta$. These curves give the land rents in different locations consistent with given utility (composite consumption) levels for the groups. Note that since $\theta<1$, the black bid-rent curve is steeper than the white curve, as noted above (the slopes are, respectively, $-t / \theta$ and $-t)$.

The bid-rent curves for the SBD workers, which are based on the SBD income levels $Y_{s}$ and $y_{s}$ and the reverse distance measure $\bar{x}-x$, are derived similarly. Note that, because workers of a given type must receive the same utility regardless of where they are employed, the utility levels $Z$ and $z$ in these formulas do not have CBD and SBD indexes.

The bid-rent curves can be used to solve for the equilibrium shown in 
figure 2, yielding solutions for $\tilde{x}, x^{*}, z$, and $Z .^{5}$ Only the $\tilde{x}$ solution is needed for the ensuing labor-market analysis, and it is easily derived. Since the bid-rent curves of black CBD and SBD commuters must intersect at $\tilde{x}$, the solution must satisfy $\left(y_{c}-t \tilde{x}-z\right) / \theta=\left[y_{s}-t(\bar{x}-\tilde{x})-\right.$ $z] / \theta$, which yields

$$
\tilde{x}=\frac{\bar{x}}{2}+\frac{\Delta y}{2 t},
$$

where $\Delta y=y_{c}-y_{s}$ denotes the black CBD-SBD income differential. Note that $\tilde{x}$ diverges from the midpoint $\bar{x} / 2$ of the city (where commuting costs to the two centers are equal) by a term that depends on the black income differential between the centers.

\section{The Minimum-Wage Framework}

\section{A. The Setup}

Black and white incomes at the two employment centers are taken as fixed in the main part of Brueckner and Martin's analysis. However, to understand the labor-market impacts of spatial mismatch, these incomes must be endogenously determined, with the possibility of unemployment affecting expected earnings. This section of the article explores a simple way of achieving this goal, relying on a minimum-wage framework.

To implement this approach, it is assumed that the urban economy has two types of jobs, one requiring high skills and the other low skills. Because poor neighborhood schools and low family incomes impede accumulation of human capital, black workers are all assumed to have low skills, while all white workers have high skills. ${ }^{6}$

Furthermore, a common minimum wage, denoted $w_{\min }$, applies to lowskill jobs at both the CBD and SBD. The minimum wage is irrelevant for white workers, whose higher skills give them an equilibrium wage above $w_{\min }$.

Employed workers lose their jobs with a constant probability per unit of time. This exogenous probability, denoted the "job separation rate," is given by $v$. The probability per unit time that a worker laid off from CBD employment regains employment at the CBD is denoted $a_{c}$, an endogenous quantity referred to as the "job acquisition rate." The corresponding rate for laid-off SBD workers is denoted $a_{s}$.

${ }^{5}$ The equilibrium conditions require that (i) the black bid-rent curves intersect at $\tilde{x}$ (the CBD-SBD commute boundary for black workers); (ii) the white bidrent curves intersect each other as well as the horizontal axis at $x^{*}$ (the latter requirement reflects a zero opportunity cost for land); and (iii) the bid-rent curve of white CBD commuters intersects the black bid-rent curves at $\tilde{x}$.

${ }^{6}$ For a model where skill differences emerge endogenously through neighborhood formation in the presence of peer group effects, see Bénabou (1993). 
A key additional assumption is that the SBD job acquisition rate for workers laid off from the CBD equals zero. Similarly, the CBD job acquistion rate for workers laid off from the SBD also equals zero. These restrictions reflect the underlying assumption that laid-off workers cannot simultaneously search for jobs at both employment centers. This assumption is motivated by evidence on the nature of job contacts for lowskill workers. In particular, numerous empirical studies (e.g., Holzer 1987, 1988) show that low-skill workers find most of their jobs through local sources of information such as word-of-mouth communication within social networks and on-site advertisements. On the employer side, Rees and Schultz (1970) and Wial (1991) show that firms prefer to use employee referrals (generated by word-of-mouth contact) to fill low-skill vacancies. High-skill workers, by contrast, are often recruited using methods such as newspaper and trade-publication advertisements, headhunting firms, and so forth, which rely less on local information.

Because laid-off CBD workers are part of a social network oriented toward the CBD, they have immediate access only to the local information pertaining to CBD jobs. As a result, they are unable to search for SBD jobs without taking additional action. Such action would involve switching their labor-market attachment to the SBD and beginning the task of acquiring local information about SBD jobs. ${ }^{7}$

Given these assumptions, the analysis effectively treats the black CBD and SBD labor markets as separate, an approach that is also followed in the efficiency-wage framework developed below. However, a crucial equilibrium condition, which is already present in the spatial model, requires that black workers attached to the CBD and SBD labor markets are equally well off. As a result, black workers in equilibrium have no incentive to switch between the two markets.

Within each labor market, layoffs must equal job acquisitions in the steady state. Letting $N_{c}$ denote the size of the black labor pool attached to the CBD and $u_{c}$ denote the unemployment rate among these workers, this requirement can be written $v\left(1-u_{c}\right) N_{c}=a_{c} u_{c} N_{c}$. Solving for $a_{c}$, the CBD job acquisition rate must satisfy $a_{c}=v\left(1-u_{c}\right) / u_{c}$, with an analogous solution holding for $a_{s}$. Rearranging the previous equation, the CBD unemployment rate can be written $u_{c}=v /\left(v+a_{c}\right)$, with an analogous relationship holding for the SBD labor market.

To determine the CBD and SBD unemployment rates that emerge in equilibrium, two additional assumptions are needed. The first is that black workers engage in income smoothing as they cycle in and out of unemployment. Thus, black workers save while employed and draw down

\footnotetext{
${ }^{7}$ Note that, since local information is related to a worker's prior employment rather than his residential location, workers living near one another (e.g., on either side of $\tilde{x}$ ) may have different information sets.
} 
their savings when out of work, with their consumption expenditure reflecting average income. This means that all black workers attached to a given center have identical disposable incomes, equal to the average income over the job cycle. To compute this income, observe that the expected durations of employment and unemployment at the CBD equal, respectively, $1 / v$ and $1 / a_{c}$. It follows that a CBD worker spends a fraction $a_{c} /\left(v+a_{c}\right)$ of his time employed. Assuming that the unemployment benefit is zero, the worker's average income over time thus equals $a_{c} w_{\min } /\left(v+a_{c}\right)$, which reduces to $\left(1-u_{c}\right) w_{\min }$ using the above equilibrium condition. ${ }^{8}$

Similarly, smoothed income for SBD workers equals $\left(1-u_{s}\right) w_{\min }$. Note that these incomes are also equal to expected income at a given point in time.

The second assumption, which concerns the transportation costs of unemployed workers, is also designed to limit heterogeneity in the model. The assumption derives from the approach of Zenou and Smith (1995), who assume that unemployed workers incur transportation costs $\alpha$ times as large as the commuting costs of employed workers, where $\alpha \leq 1$. These costs capture the cost of job search at the employment center as well as the cost of shopping trips, which are combined with commute trips by employed workers. To make the present analysis manageable, the assumption $\alpha=1$ is required, indicating that unemployed workers travel to the job center just as frequently as those who are employed, carrying out job search, shopping, and other nonwork activities. Under this assumption, all workers residing at a given location incur the same transportation cost regardless of their employment status. Since these individuals also pay the same land rent, all location-related costs are invariant to employment status, as is income. This conclusion means that the minimum-wage framework can be inserted directly into the spatial model, with $y_{c}=\left(1-u_{c}\right) w_{\min }$ and $y_{s}=\left(1-u_{s}\right) w_{\min }$ and no further changes required.

\section{B. Unemployment Solutions}

With this background, the equilibrium unemployment rates at the $\mathrm{CBD}$ and SBD can be characterized and easily compared. First, let $F(L)$ denote the black portion of the separable production function, which is common to both employment centers. The variable $L$ denotes labor input, and $F$

${ }^{8}$ A zero interest rate on savings is assumed for the purposes of income smoothing. In contrast to the above approach, other spatial models explicitly incorporate the heterogeneity of the employed and unemployed, whose different incomes and commuting costs lead them to occupy different areas of the city. See Zenou and Smith (1995) and Brueckner and Zenou (1999). 
is increasing and strictly concave. Then, under the minimum wage, the quantity of labor demanded at each center, denoted $\bar{L}$, satisfies

$$
F^{\prime}(\bar{L})=w_{\min }
$$

Next, recalling that black CBD workers live between $x=0$ and $x=\tilde{x}$, each consuming $\theta$ units of land, the CBD labor pool size equals

$$
N_{c}=\tilde{x} / \theta,
$$

while the SBD labor pool is given by

$$
N_{s}=N-\tilde{x} / \theta,
$$

where $N$ again is the total black population. Since employment at each center must equal labor demand, the equilibrium unemployment rates satisfy

$$
\begin{aligned}
& \left(1-u_{c}\right) N_{c}=\bar{L}, \\
& \left(1-u_{c}\right) N_{s}=\bar{L} .
\end{aligned}
$$

Finally, $\tilde{x}$ must satisfy (1) with $\Delta y=\left(1-u_{c}\right) w_{\min }-\left(1-u_{s}\right) w_{\min }$, or

$$
\tilde{x}=\frac{\bar{x}}{2}+\frac{\left(u_{s}-u_{c}\right) w_{\min }}{2 t} .
$$

Together, (3)-(7) determine equilibrium values for $u_{c}, u_{s}, \tilde{x}, N_{c}$, and $N_{s \cdot}{ }^{9}$ Using these equations, the following result can be established:

Proposition 1. Suppose that the minimum wage is high enough to generate black unemployment at both centers. Then $u_{c}>u_{s}$ holds in equilibrium, as does $N_{c}>N_{s}$.

Proof. Suppose to the contrary that $u_{c} \leq u_{s}$ holds. Then, for (5) and (6) to be satisfied, $N_{c} \leq N_{s}$ must hold, implying that $\tilde{x} / \theta \leq N-\tilde{x} / \theta$ from (3) and (4). This inequality, in turn, yields $N \geq 2 \tilde{x} / \theta \geq \bar{x} / \theta$, where the second inequality makes use of (7). But the last inequality implies that $\theta N \geq \bar{x}$, which means that the black population occupies a land area that is least as large as the area of the city, an impossibility. Thus, $u_{c}<u_{s}$ must hold, and $N_{c}>N_{s}$ follows from (5) and (6). Q.E.D.

Proposition 1 shows that, under the minimum-wage model, the black CBD unemployment rate exceeds the suburban rate, in conformance with the evidence presented earlier. Recall that table 3 showed a $12.5 \%$ un-

${ }^{9}$ Existence and uniqueness of the equilibrium can be established. A proof is available from the authors on request. 
employment rate among central city blacks, with black suburban workers experiencing a much-lower $7.6 \%$ rate. $^{10}$

To gain further insight into this result, it is helpful to compare the unemployment rates in the unrestricted equilibrium shown in figure 1, where suburban housing discrimination is absent, with those in the restricted case analyzed above. Since the black labor force is equally divided between the CBD and SBD in the unrestricted case, the centers have a common unemployment rate $\hat{u}$, which satisfies $(1-\hat{u}) N / 2=\bar{L}$. Then, proposition 1 along with (5) and (6) yield the following conclusion:

Proposition 2. The common black unemployment rate $\hat{u}$ at the two centers in the unrestricted equilibrium lies between the CBD and SBD unemployment rates in the restricted equilibrium, so that

$$
u_{c}>\hat{u}>u_{s} \text {. }
$$

Propositions 1 and 2 show that suburban housing discrimination affects labor-market outcomes at the two centers. The unemployment rate rises at the $\mathrm{CBD}$ relative to the unrestricted case, while the reverse effects occur at the SBD. The explanation is straightforward: by keeping black residences in close proximity to the CBD (and remote from the SBD), suburban housing discrimination enlarges the black CBD labor pool relative to the SBD pool. With the common minimum wage leading to identical, fixed labor demands at both centers, the consequence is higher unemployment at the $\mathrm{CBD}$ relative to the $\mathrm{SBD}$. Thus, the results generate a link between unemployment and a seemingly unrelated phenomenon: racial discrimination in the housing market. The analysis shows that these phenomena are connected, a novel finding that is absent in previous theoretical work on spatial mismatch.

A drawback to the analysis, however, is use of a minimum-wage model, where unemployment is generated as a result of an artificial restriction on wages. The above results would have greater value if they could be generated in an equilibrium framework where unemployment emerges without the use of artificial elements. An attractive framework with this property is the efficiency-wage model, where unemployment serves as a worker discipline device. The next section of this article shows that results

${ }^{10}$ A subtle point arises once this correspondence is noted. In particular, while the unemployment differential in the model is based on place of work, that in table 3 is based on place of residence. If the central city-suburban boundary were located at $\tilde{x}$ in fig. 2, then the two criteria would be identical (all black CBD workers would live in the "central city," while all white workers would live in the "suburbs"). This equivalence will be disrupted, however, with a different boundary location. Nevertheless, if the suburban boundary is located somewhere in the black area, then even though black suburban residents may include some central city workers (or vice versa), it will remain true that suburban residents have a lower (average) unemployment rate than central city residents. 
like those derived above also emerge in such a model, demonstrating the robustness of this article's basic insight. In addition, the analysis generates realistic wage differences between the employment centers, further strengthening the link to the empirical literature.

\section{The Efficiency-Wage Framework}

\section{A. The Setup}

To adapt the efficiency wage model to the present setting, it is assumed that shirking may occur in the low-skill job, while high-skill workers do not have the opportunity to shirk. As a result, efficiency wages must be paid to prevent low-skill shirking, while high-skill wages are determined by the usual marginal productivity conditions. Given the economy's assumed skill distribution, it follows that black workers are paid efficiency wages while white workers are not. Thus, the black workers in the model are doubly disadvantaged by housing-market discrimination and by the need to work at jobs where efficiency wages, and the associated unemployment, are required to maintain worker effort.

Although this structure is meant to reproduce the stylized facts of high black and low white unemployment, it could be assumed that efficiency wages are also paid to white workers, but that different job characteristics allow deterrence of shirking with relatively low white unemployment levels. In any case, it should be recognized that the potential for shirking is a characteristic of jobs and not a racial attribute. ${ }^{11}$

To facilitate the discussion, it is useful to review the elements of the efficiency-wage model of Shapiro and Stiglitz (1984) that is used in the analysis. ${ }^{12}$ In the model, a worker can expend an effort level of $e>0$ or shirk, which means setting effort at zero. Effort is viewed as generating an explicit dollar cost for the worker, so that a nonshirker's job income is equal to the wage minus $e .^{13}$

The firm monitors its work force, catching shirkers with a fixed probability $m$ per unit time, and apprehended shirkers are fired, earning the zero unemployment benefit. Since shirkers contribute nothing to the employer's output, the firm offers incentives to make shirking unattractive. This involves setting a wage high enough so that, given the prevailing level of unemployment, the loss from being caught and fired offsets the

${ }^{11}$ It should be noted that the reverse assumptions on shirking are often imposed, with shirking possible in high-skill but not in low-skill jobs (see, e.g., Bulow and Summers 1986). One justification for the current approach is that low-skill jobs are more often found in large firms, where monitoring is relatively difficult.

${ }^{12}$ If there exists a separate low-skill labor market where shirking is not possible, then the results of the standard efficiency-wage are overturned. See Bulow and Summers 1986.

${ }^{13}$ The cost of effort is normalized to unity. Equivalently, effort can appear as a negative linear term in the utility function. 
worker's cost of exerting effort. In addition to being fired for shirking, workers also face the threat of exogenous job separation, which occurs with probability $v$ per unit of time, as in the minimum-wage analysis.

Adapting Shapiro and Stiglitz's (1984) derivation to the present setting, it can be shown that the CBD efficiency wage is given by: ${ }^{14}$

$$
w_{c}=e+\frac{e v}{m u_{c}} \text {. }
$$

Inspection of (9) shows that the efficiency wage is an increasing function of effort $e$ and the job separation rate $v$. The wage is also decreasing in monitoring efficiency $m$ and the unemployment rate $u_{c}$. Note that an increase in either of the latter variables raises the potential loss from shirking, allowing the firm to pay a lower wage while still eliciting effort from the worker. Observe also that land rent and transportation costs do not appear in (9). Because they are identical for employed and unemployed workers, these expenditures cancel in the calculation of the efficiency wage. ${ }^{15}$

Finally, note that the CBD and SBD black labor markets are again treated as separate via the assumption that cross-center job acquisition rates are zero. As before, however, workers attached to the two centers must be equally well off in equilibrium, eliminating any incentive to switch centers.

The next step is to note that firms adjust employment until the marginal product of an additional worker equals the efficiency wage. Each firm views the unemployment rate upon which the efficiency wage depends as parametric and uninfluenced by its input choice. Labor input at the CBD then satisfies $F^{\prime}\left(L_{c}\right)=w_{c}$, where $w_{c}$ is given by (9). Since $L_{c}=$ $\left(1-u_{c}\right) N_{c}$, where $N_{c}$ again denotes the size of the CBD labor pool, the previous equality can be written as

$$
F^{\prime}\left[\left(1-u_{c}\right) N_{c}\right]=e+\frac{e v}{m u_{c}} .
$$

Equation (10) determines the equilibrium unemployment rate. Note that a high $u_{c}$ decreases the efficiency wage, encouraging firms to hire more workers, while at the same time decreasing the number of workers presumed to be employed. Equilibrium is achieved when these two effects are in balance. Repeating all the above analysis for the SBD labor market,

\footnotetext{
${ }^{14}$ The derivation yields the standard efficiency-wage formula, but a zero value for the interest rate is inserted, reflecting the simplifying assumption introduced above (see n. 8).

${ }^{15}$ Without this cancellation, which relies on the assumption that transportation costs are identical for employed and unemployed workers, it would be impossible to derive a common efficiency wage that applies to all locations.
} 
yields an efficiency-wage solution like (9) along with the equilibrium condition

$$
F^{\prime}\left[\left(1-u_{s}\right) N_{s}\right]=e+\frac{e v}{m u_{s}} .
$$

As before, workers are assumed to smooth their incomes as they cycle in and out of unemployment, a cycling that is due solely to exogenous job separation. This smoothing now yields incomes of $y_{c}=(1-$ $\left.u_{c}\right)\left(w_{c}-e\right)$ and $y_{s}=\left(1-u_{s}\right)\left(w_{s}-e\right)$ for CBD and SBD workers (recall from above that effort entails an explicit cost that reduces the net wage). Using the efficiency-wage solutions to eliminate $w_{c}$ and $w_{s}$ from these equations, they can be rewritten as

$$
\begin{aligned}
& y_{c}=\frac{e v\left(1-u_{c}\right)}{m u_{c}}, \\
& y_{s}=\frac{e v\left(1-u_{s}\right)}{m u_{s}} .
\end{aligned}
$$

As in the minimum-wage model, the labor-market equilibrium conditions, equations (10)-(13), are supplemented by the equations of the spatial model, (3) and (4) along with the condition determining $\tilde{x}$. The latter condition is given by (1), with $\Delta y$ equal to the difference between (8) and (13). These equations constitute seven conditions that determine equilibrium values for the variables $u_{c}, u_{s}, y_{c}, y_{s}, N_{c}, N_{s}$, and $\tilde{x}^{16}$

It is useful to note how the above conditions would be affected if the production function were nonseparable, eliminating the separation of the black and white labor markets. In this case, the number of white CBD workers $\left(K_{c}\right)$ would be an argument of the black marginal product expression on the left-hand side of (10), while the analogous variable $K_{s}$ would appear in (11). In addition, white wages at the two centers would equal white marginal products, which would depend at each center on the inputs of both types of labor. Finally, $K_{c}$ would equal $x^{*}-\theta N$ (see fig. 2), while $K_{s}$ would equal $\bar{x}-x^{*}$, with $x^{*}$ itself depending on the white income differential between the centers. When these additional conditions are added to the above equilibrium conditions, the resulting complexity prevents derivation of many of the ensuing results. One key result, however, is unaffected, as noted below.

${ }^{16}$ Existence and uniqueness of the equilibrium can again be established. The proof is available from the authors on request. 


\section{B. Analysis of the Equilibrium}

In the minimum-wage analysis of Section III, spatial mismatch led to an unemployment-rate differential for blacks between the CBD and SBD. The key question is whether a similar differential emerges in a model where wages are not artificially fixed. The following proposition gives an affirmative answer to this question for the efficiency-wage model while establishing a number of additional results:

Proposition 3. For black workers, the CBD has a higher unemployment rate, a lower wage and smoothed income, a larger labor pool, and a higher employment level than the SBD. In other words,

$$
\begin{aligned}
u_{c} & >u_{s} \\
w_{c} & <w_{s} \\
y_{c} & <y_{s} \\
N_{c} & >N_{s} \\
\left(1-u_{c}\right) N_{c} & >\left(1-u_{s}\right) N_{s} .
\end{aligned}
$$

Proof. Suppose that, contrary to (16), $\Delta y=y_{c}-y_{s} \geq 0$. Then, since the expressions on the right-hand side of (12) and (13) are decreasing in the respective unemployment rates, it follows that $u_{c} \leq u_{s}$. But since the right-hand side expressions in (10) and (11) are also decreasing in the $u^{\prime}$ 's, this implies that $w_{c}=F^{\prime}\left[\left(1-u_{c}\right) N_{c}\right] \geq F^{\prime}\left[\left(1-u_{s}\right) N_{s}\right]=w_{s}$ must hold. From strict concavity of $F$, it then follows that $\left(1-u_{c}\right) N_{c} \leq\left(1-u_{s}\right) N_{s}$. However, given $u_{c} \leq u_{s}$, the only way the previous inequality can hold is if $N_{c} \leq N_{s}$. Since (1) implies that $\tilde{x} \geq \bar{x} / 2$ given $\Delta y \geq 0$, it follows (as before) that the blacks occupy more land than is available in the city. Thus, $\Delta y<0$ must hold instead, which reverses all of the relevant inequalities above, establishing the proposition. Q.E.D.

Proposition 3 shows that workers attached to the CBD experience worse labor-market outcomes than SBD workers. These workers, who outnumber those attached to the SBD, experience a higher unemployment rate, a lower wage, and a lower smoothed income. Once again, the gap between CBD and SBD unemployment rates generated by the model mirrors the real-world pattern. In addition, the CBD-SBD wage differential implied by the model, where black workers earn less at the CBD, also conforms to existing evidence. See, for example, Price and Mills (1985), who find a 5\%-6\% CBD-SBD wage differential.

As before, insight into the above results can be gained by comparing the restricted equilibrium with the unrestricted equilibrium, where housing discrimination is absent. Since the unrestricted equilibrium is symmetric, each center's labor pool contains half of the black population. The 
common unemployment rate, again denoted $\hat{u}$, is then determined by the condition

$$
F^{\prime}[(1-\hat{u}) N / 2]=e+\frac{e v}{m \hat{u}} .
$$

The following conclusions then apply:

Proposition 4. As in the minimum wage model, the common unemployment rate $\hat{u}$ at the two centers in the unrestricted equilibrium lies between the CBD and SBD unemployment rates in the restricted equilibrium, with (8) holding. The same conclusion applies to the common wage $\hat{w}$, smoothed income $\hat{y}$, labor pool $N / 2$, and employment level $(1-\hat{u}) N / 2$ at the two centers in the unrestricted equilibrium, each of which lies between the CBD and SBD values in the restricted equilibrium.

Proof. The appendix provides a proof of this and all subsequent results.

Parallel conclusions, summarized in propositions 1 and 2, were reached in the minimum-wage analysis, and the intuitive explanation for those results was transparent. With suburban housing discrimination skewing the black labor force skewed toward the CBD, a higher unemployment rate emerged at that center. Since the endogeneity of wages complicates the picture in the efficiency-wage framework, this simple intuition does not automatically apply. However, essentially the same mechanism underlies the CBD-SBD unemployment differential in the current setting. The reason is that, with wages adjusting endogenously, the equilibrium unemployment rate nevertheless depends on the size of the labor pool, just as in the minimum-wage model. This can seen in the CBD case by treating $N_{c}$ as exogenous and differentiating (10), which yields

$$
\frac{\partial u_{c}}{\partial N_{c}}=\frac{\left(1-u_{c}\right) F^{\prime \prime}}{N_{c} F^{\prime \prime}-e v / m u_{c}^{2}}>0,
$$

establishing that a larger pool raises the unemployment rate. The intuitive explanation is that as $N_{c}$ rises, the wage must fall to encourage firms to absorb more workers. But given the efficiency-wage solution in (9), this requires a larger $u_{c}$. Note that the higher unemployment rate raises the penalty from job termination, maintaining the incentive against shirking as the wage falls. When combined with the mismatch-induced expansion of the CBD labor pool, and the offsetting contraction of the SBD pool, the effect in (20) accounts for the unemployment-rate differential between the two centers.

It should be noted that this unemployment effect persists under more general assumptions. In particular, if the production function, instead of being separable in white and black labor, is nonseparable but homothetic, then it can be shown that $u_{c}>\hat{u}>u_{s}$ continues to hold. It is interesting, 
however, that the results in (15)-(18) for the other endogenous variables do not necessarily carry over to this more general case.

Although spatial mismatch raises the unemployment rate among black workers attached to the CBD, what can be said about the effect on the total number of unemployed black workers in the city? The total number of unemployed, denoted $U$, is equal to

$$
U=u_{c} N_{c}+u_{s} N_{s} .
$$

In order to compare the value of $U$ in the unrestricted equilibrium to the value in the restricted case, let $N_{c}$ and $N_{s}$ be replaced by $N / 2+\lambda$ and $N / 2-\lambda$, where $\lambda>0$ given (17). Substituting these expressions in place of $N_{c}$ and $N_{s},(10)$ and (11) then determine $u_{c}$ and $u_{s}$ as functions of $\lambda$, with the unrestricted case corresponding to $\lambda=0$. Total unemployment in (21) can then be written as

$$
U(\lambda)=u_{c}(\lambda)(N / 2+\lambda)+u_{s}(\lambda)(N / 2-\lambda) .
$$

Using this approach, it can be shown that spatial mismatch raises total black unemployment in the city relative to the unrestricted case, in the following sense:

Proposition 5. The relationships $U^{\prime}(0)=0$ and $U^{\prime \prime}(0)>0$ hold, indicating that total unemployment reaches a local minimum at $\lambda=0$, provided that the elasticity of $F^{\prime \prime}$ with respect to its argument exceeds or equals -2 .

The elasticity condition on $F$ in proposition 5 is weak, being satisfied by common functional forms such as the log function and power function. When the condition holds, proposition 5 shows that the change from a zero to a positive value of $\lambda$, which corresponds to a movement from the unrestricted to the restricted equilibrium, is likely to raise total unemployment in the city. However, because proposition 5 says that $\lambda=0$ represents a local minimum for total unemployment, the higher $U$ is guaranteed only if the divergence between $N_{c}$ and $N_{s}$ is not too large. Otherwise, the implied $\lambda$ may be far enough from zero that the local result ceases to hold.

The severity of the distortion caused by suburban housing discrimination depends on the magnitude of the commuting cost parameter $t$. A larger value for this parameter effectively increases the remoteness of the SBD from the black residential area. Intuition suggests that this effect should increase the extent to which the black labor force is skewed toward the CBD, amplifying the disparities between the two labor markets documented in proposition 3. This conclusion is proved by comparativestatic analysis of the restricted equilibrium, which establishes the following results:

Proposition 6. An increase in the commuting cost parameter $t$ leads 
to a higher unemployment rate at the $\mathrm{CBD}$ and a lower rate at the SBD, with

$$
\frac{\partial u_{c}}{\partial t}>0, \quad \frac{\partial u_{s}}{\partial t}<0
$$

Wages and smoothed incomes show corresponding changes, falling at the $\mathrm{CBD}$ and rising at the SBD, while the labor pools and total employment rise at the $\mathrm{CBD}$ and fall at the SBD.

As conjectured, proposition 6 shows that the divergence in unemployment rates, wages, and smoothed incomes between the two centers, as documented in proposition 3 , is more pronounced when the cost of commuting is high. Thus, the effects of spatial mismatch are magnified when the friction of space, as captured in the $t$ parameter, is more substantial.

Although proposition 6 shows the effect of reducing the common level of transport costs for all workers in the city, it echoes a recommendation of a number of studies in the mismatch literature: cutting the transport costs of central city residents, especially blacks, as a means of easing the effects of spatial mismatch (see Ihlanfeldt and Sjoquist 1998; Pugh 1998). ${ }^{17}$

This recommendation grows out of the observation that public-transit access from downtown to many suburban locations is inconvenient or impossible, and that public investment to improve access may lead to better labor-market outcomes for central-city residents. The model supports this idea, showing that by decreasing $t$, an improvement in the transportation network reduces the gap between CBD and SBD unemployment rates. ${ }^{18}$

\section{Welfare Effects of Spatial Mismatch}

The analysis so far has abstracted from the welfare effects of spatial mismatch. To appraise these effects, the equilibrium black consumption

${ }^{17}$ In fact, the model can be modified so that this recommendation is exactly relevant. In particular, propositions 3-6 are unaffected if the model is developed under the assumption that $t$ differs between blacks and whites, presumably being higher for blacks.

${ }^{18}$ It is interesting to observe that policy makers are beginning to pay more attention to the transportation challenges faced by low-income central city residents. New programs to address these problems are targeted specifically at former welfare recipients, while others serve broader segments of the working poor. In addition, a number of states and counties have used welfare block grants and other federal funds to support urban transportation services for welfare recipients. Moreover, Congress has created a $\$ 750$ million competitive grant program (called Access to Jobs) to fund transportation services for low-income workers (see Pugh [1998] for a complete description of these programs). 
level must be computed. As shown by Brueckner and Martin, black consumption in the unrestricted equilibrium is given by

$$
\hat{z}=\left[\hat{y}_{\mathrm{c}}+\hat{y}_{\mathrm{s}}-t \theta(N+K)\right] / 2,
$$

where $\hat{y}_{c}$ and $\hat{y}_{s}$ are unrestricted CBD and SBD incomes. Consumption in the restricted equilibrium shown in figure 2 equals

$$
z=\left[(1+\theta) y_{\mathrm{c}}+(1-\theta) y_{\mathrm{s}}-\theta \Delta Y-t \bar{x}\right] / 2,
$$

where $\Delta Y$ is the white CBD-SBD income differential. To compare (24) and (25), Brueckner and Martin consider the case without unemployment where incomes are fixed and thus invariant between equilibria (so that $\hat{y}_{c}=y_{c}$ and $\hat{y}_{s}=y_{s}$ ). In this case, they show that $\hat{z}$ exceeds $z$ under the income conditions that generate the commuting pattern in figure 2 (with both groups commuting to both centers). Thus, spatial mismatch harms black workers, confirming expectations.

When incomes are endogenous, however, and thus different across equilibria, an analytical comparison of (24) and (25) is impossible. Using simulation analysis, Brueckner and Martin carried out this comparison numerically, assuming a market-clearing model of wage determination, and found that mismatch again hurts blacks. Such a numerical approach is also required to conduct welfare analysis in the present context. In unreported simulations based on the efficiency-wage model, the expected welfare result again emerges. The $\hat{z}$ solution in (24) exceeds $z$ from (25) under a variety of parameter values, showing that spatial mismatch reduces black welfare. Such numerical findings, of course, do not constitute a proof of this claim.

\section{Conclusion}

This article has provided a new theoretical analysis of the labor-market effects of spatial mismatch. The analysis is novel because these labormarket impacts arise from the spatial side of the model, where suburban housing discrimination concentrates black residences near the CBD. Because of the resulting remoteness of the suburban employment center, the black labor force is skewed toward the CBD labor market, and this in turn generates a host of labor-market effects. These include a higher black unemployment rate and a lower wage at the CBD. The analysis thus draws a connection between "space" and unemployment, providing the first well-rounded theoretical treatment of this important element of the spatial mismatch hypothesis.

Further work could be devoted to development of other models that deepen our understanding of spatial mismatch. An important element missing from the current framework is job search, and further work could attempt to integrate the search process into a spatial model that also 
incorporates suburban housing discrimination, following the lead of Coulson et al. (2001). Another exercise could explore the effect of a gradual weakening of suburban discrimination within the current framework. This phenomenon could be modeled as a gradual shrinkage of the area where discrimination occurs, which would contract toward the SBD. While such an exercise would be complex, it would offer a useful picture of the transition to an urban economy where spatial mismatch is absent.

\section{Appendix}

\section{Proofs of Propositions}

Proof of proposition 4. To establish (8) for the efficiency wage model, suppose that $\hat{u} \geq u_{c}$ holds. Then, noting that (17) implies that $N_{c}>$ $N / 2>N_{s}$, it follows that $(1-\hat{u}) N / 2<\left(1-u_{c}\right) N_{c}$ holds. But, given $F^{\prime \prime}<$ 0 , this inequality implies that the right-hand side of (10) exceeds the righthand side of (19), contradicting the assumption that $\hat{u} \geq u_{c}$. Since $u_{s} \geq \hat{u}$ leads to a similar contradiction, (8) follows. The results on $\hat{w}, \hat{y}$, and $(1-\hat{u}) N / 2$ then follow directly. Q.E.D.

Proof of proposition 5. Note from (22) that

$$
U^{\prime}(\lambda)=u_{c}-u_{s}+\frac{N}{2}\left[\frac{\partial u_{c}}{\partial \lambda}+\frac{\partial u_{s}}{\partial \lambda}\right]+\lambda\left[\frac{\partial u_{c}}{\partial \lambda}-\frac{\partial u_{s}}{\partial \lambda}\right]
$$

Since $u_{c}=u_{s}=\hat{u}$ when $\lambda=0$, and since $\partial u_{c} / \partial \lambda$ and $\partial u_{s} / \partial \lambda$ are equal and opposite in sign in this case, it follows that $U^{\prime}(0)=0$. Differentiating (A1) and evaluating the result at $\lambda=0$ yields

$$
U^{\prime \prime}(0)=2\left[\frac{\partial u_{c}}{\partial \lambda}-\frac{\partial u_{s}}{\partial \lambda}\right]+\frac{N}{2}\left[\frac{\partial^{2} u_{c}}{\partial \lambda^{2}}+\frac{\partial^{2} u_{s}}{\partial \lambda^{2}}\right]
$$

The derivative in (20) (with $n=N / 2$ ) gives $\partial u_{c} / \partial \lambda$ evaluated at $\lambda=0$, which in turn equals $-\partial u_{s} / \partial \lambda$. Equation (20) is also used to compute the second derivatives in (A2), which are equal when evaluated at $\lambda=0$. After substitution of the resulting expressions, extensive and tedious manipulations show that (A2) reduces to an expression with the sign of

$$
\frac{e v}{m \hat{u}}(1+\epsilon / 2)-(N / 2) F^{\prime \prime}
$$

where $\epsilon=F^{\prime \prime \prime}[(1-\hat{u}) N / 2] / F^{\prime \prime}$ is the elasticity of $F^{\prime \prime}$ evaluated at $\lambda=0$. Proposition 5 follows from inspection of (A3). Q.E.D. 
Proof of proposition 6. The first step is to use (3) and (4) to eliminate $N_{c}$ and $N_{s}$ in (10) and (11), which allows these equations to be written as

$$
\begin{aligned}
& \Gamma=F^{\prime}\left[\left(1-u_{c}\right) \frac{\Delta y+t \bar{x}}{2 \theta t}\right]-e-\frac{e v}{m u_{c}}=0, \\
& \Phi=F^{\prime}\left[\left(1-u_{s}\right)\left(N-\frac{\Delta y+t \bar{x}}{2 \theta t}\right)\right]-e-\frac{e v}{m u_{s}}=0,
\end{aligned}
$$

where

$$
\Delta y=\frac{e v}{m}\left[\frac{1-u_{c}}{u_{c}}-\frac{1-u_{s}}{u_{s}}\right] .
$$

Differentiating (A4) and (A5) yields the following results (subscripts denote partial derivatives):

$$
\begin{aligned}
& \Gamma_{u_{c}}=-\frac{F^{\prime \prime}}{2 \theta t}\left(\Delta y+t \bar{x}+\frac{\left(1-u_{c}\right) e v}{m u_{c}^{2}}\right)+\frac{e v}{m u_{c}^{2}} \\
& \Gamma_{u_{s}}=\frac{F^{\prime \prime}}{2 \theta t} \frac{\left(1-u_{c}\right) e v}{m u_{s}^{2}} \\
& \Gamma_{t}=-\frac{F^{\prime \prime}}{2 \theta t^{2}}\left(1-u_{c}\right) \Delta y \\
& \Phi_{u_{c}}=\frac{F^{\prime \prime}}{2 \theta t} \frac{\left(1-u_{s}\right) e v}{m u_{c}^{2}} \\
& \Phi_{u_{s}}=-\frac{F^{\prime \prime}}{2 \theta t}\left[2 \theta t N-\Delta y-t \bar{x}+\frac{\left(1-u_{s}\right) e v}{m u_{s}^{2}}\right]+\frac{e v}{m u_{s}^{2}} \\
& \Phi_{t}=\frac{F^{\prime \prime}}{2 \theta t^{2}}\left(1-u_{s}\right) \Delta y .
\end{aligned}
$$

Application of Cramer's rule then yields

$$
\begin{aligned}
& \frac{\partial u_{c}}{\partial t}=\frac{\Gamma_{u_{s}} \Phi_{t}-\Gamma_{t} \Phi_{u_{s}}}{\Gamma_{u_{c}} \Phi_{u_{s}}-\Gamma_{u_{s}} \Phi_{u_{c}}} \\
& \frac{\partial u_{s}}{\partial t}=\frac{\Gamma_{t} \Phi_{u_{c}}-\Gamma_{u_{c}} \Phi_{t}}{\Gamma_{u_{c}} \Phi_{u_{s}}-\Gamma_{u_{s}} \Phi_{u_{c}}} .
\end{aligned}
$$

Using (A7)-(A12), tedious but routine computations show that the denominator expression in (A13) and (A14) is positive. Similar calculations show that the numerator expression in (A13) is positive, yielding $\partial u_{c} / \partial t>0$, and that the numerator expression in (A14) is negative, yielding $\partial u_{s} / \partial t<0$. The remainder of proposition 6 follows from (10)-(13). Q.E.D. 


\section{References}

Anas, Alex. "Prejudice, Discrimination and Spatial Mismatch." Unpublished manuscript. Buffalo: State University of New York at Buffalo, Department of Economics, 1998.

Arnott, Richard. "Economic Theory and the Spatial Mismatch Hypothesis." Urban Studies 35 (June 1998): 1171-85.

Bénabou, Roland. "Workings of a City: Location, Education, and Production.” Quarterly Journal of Economics 108 (August 1993): 619-52.

Brueckner, Jan K., and Martin, Richard W. "Spatial Mismatch: An Equilibrium Analysis." Regional Science and Urban Economics 27 (November 1997): 693-714.

Brueckner, Jan K., and Zenou, Yves. "Harris-Todaro Models with a Land Market." Regional Science and Urban Economics 29 (May 1999): 317-39.

Bulow, Jeremy, and Summers, Lawrence. "A Theory of Dual Labor Markets with Applications to Industrial Policy, Discrimination, and Keynesian Unemployment." Journal of Labor Economics 4 (July 1986): 376-414.

Coulson, N. Edward; Laing, Derek; and Wang, Ping. "Spatial Mismatch in Search Equilibrium." Journal of Labor Economics 19 (October 2001): 949-72.

Cutler, David M., and Glaeser, Edward L. "Are Ghettos Good or Bad?” Quarterly Journal of Economics 112 (August 1997): 827-72.

Holzer, Harry. "Informal Job Search and Black Youth Unemployment." American Economic Review 77 (June 1987): 446-52.

_ . "Search Methods Used by Unemployed Youth." Journal of Labor Economics 6 (January 1988): 1-20.

- "The Spatial Mismatch Hypothesis: What Has the Evidence Shown?” Urban Studies 28 (February 1991): 105-22.

Ihlanfeldt, Keith R., and Sjoquist, David L. "Job Accessibility and Racial Differences in Youth Unemployment Rates." American Economic Review 80 (March 1990): 267-76.

— "The Spatial Mismatch Hypothesis: A Review of Recent Studies and Their Implications for Welfare Reform." Housing Policy Debate 9, no. 4 (1998): 849-92.

Kain, John F. "Housing Segregation, Negro Employment, and Metropolitan Decentralization." Quarterly Journal of Economics 82 (February 1968): 32-59.

- "The Spatial Mismatch Hypothesis: Three Decades Later." Housing Policy Debate 3, no. 2 (1992): 371-460.

Martin, Richard W. "Job Decentralization with Suburban Housing Discrimination: An Urban Equilibrium Model of Spatial Mismatch." Journal of Housing Economics 6 (December 1997): 293-317.

Price, Richard, and Mills, Edwin S. "Race and Residence in Earnings Determination." Journal of Urban Economics 17 (January 1985): 1-18.

Pugh, Margaret. "Barriers to Work: The Spatial Divide between Jobs and 
Welfare Recipients in Metropolitan Areas.” Unpublished manuscript. Washington, DC: Brookings Institution, 1998.

Raphael, Steven. "The Spatial Mismatch Hypothesis and Black Youth Joblessness: Evidence from the San Francisco Bay Area." Journal of Urban Economics 43 (January 1998): 79-111.

Rees, Albert, and George Schultz. Workers and Wages in an Urban Labor Market. Chicago: University of Chicago Press, 1970.

Shapiro, Carl, and Stiglitz, Joseph E. "Equilibrium Unemployment as a Worker Discipline Device.” American Economic Review 74 (June 1984): 433-44.

Smith, Tony E., and Zenou, Yves. "Dual Labor Markets, Urban Unemployment, and Multicentric Cities." Journal of Economic Theory 76 (September 1997): 185-214.

Stanback, Thomas M. The New Suburbanization. Boulder, CO: Westview, 1991.

Weinberg, Bruce A. "Black Residential Centralization and the Spatial Mismatch Hypothesis." Journal of Urban Economics 48 (July 2000): 110-34.

Wial, Howard. "Getting a Good Job: Mobility in a Segmented Labor Market.” Industrial Relations 30 (Fall 1991): 396-416.

Yinger, John. "Measuring Racial Discrimination with Fair Housing Audits." American Economic Review 76 (September 1986): 881-93.

- "Cash in Your Face: The Cost of Racial and Ethnic Discrimination in Housing." Journal of Urban Economics 42 (November 1997): 339-65.

Zax, Jeffrey S., and Kain, John F. "Moving to the Suburbs: Do Relocating Employees Leave Their Black Employees Behind?” Journal of Labor Economics 14 (July 1996): 472-504.

Zenou, Yves, and Smith, Tony E. "Efficiency Wages, Involuntary Unemployment, and Urban Spatial Structure." Regional Science and Urban Economics 25 (August 1995): 547-73. 